\title{
Tsunami damage was enhanced by coral theft
}

Illegal removal of coral along Sri Lanka's coastline increased the amount of destruction wrought on the island by last December's tsunami, say researchers.

Harindra Fernando, a fluid dynamicist at Arizona State University in Tempe, made the connection after a visit to his native Sri Lanka earlier this year. While serving as a scientific expert and translator for a BBC-documentary team, he chatted with locals who said they saw the tsunami deflect sideways when it hit coral - which would have made it less powerful than in coral-free areas. Fernando linked this to trucks he had seen last year carrying mounds of coral away from the sea.

Using the eyewitness reports, estimates of wave heights, and a series of dives to verify the presence or absence of corals, Fernando and his colleagues produced a map of coral gaps and wave inundation along Sri Lanka's southwest coast (H. S. J. Fernando et al. Eos 86, 301, 304; 2005).

The tsunami reached significantly farther inland through the gaps: in one instance a jet of water 1.5 kilometres long knocked a passenger train off its tracks, killing 1,700. But only a few kilometres away, where the coral was still intact, the wave travelled just 50 metres inland and caused no deaths.

There is a precedent for this phenomenon. In Nicaragua in 1992, a tsunami surged through a break in the coral reef made to let boats through. "Within this passage, water went one kilometre inland," says Fernando. "But nearby, where the coral was intact, there were still beach umbrellas standing."

In Sri Lanka, coral is illegally mined to provide souvenirs for tourists, or to be ground up for use in house paint. Coral harvesters sometimes blow the reefs up with dynamite in order to collect fish at the same time. Often, the reefs in the best shape are those in front of hotels, as the hotel owners maintain them for the tourists. Fernando hopes that his finding will encourage the Sri Lankan government to enforce its laws against coral mining.
Policy may very well change, says M. Sanjayan, an ecologist with the Nature Conservancy, who surveyed the environmental damage after the tsunami. "There has been a groundswell of support in Sri Lanka for better enforcement of laws," he says. "There is a window of opportunity right now."

\section{Emma Marris}

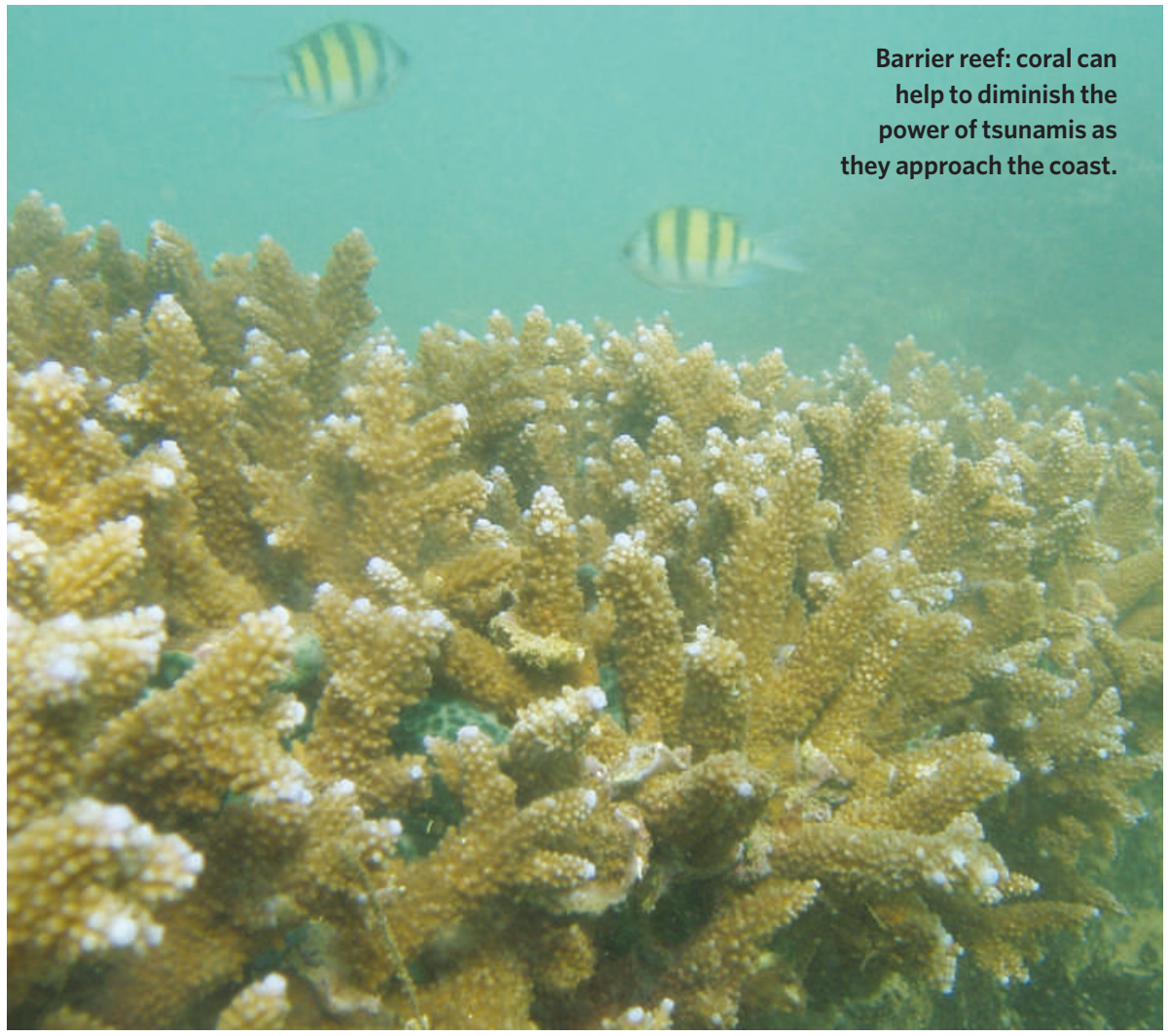

\section{Dalai Lama gets go-ahead for meditation lecture}

The Dalai Lama will speak at this year's annual meeting of the Society for Neuroscience ( $\mathrm{SfN}$ ) despite a petition calling for the lecture to be cancelled.

Campaigners had collected more than 500 signatures in protest against the talk, which they presented to the society's president, Carol Barnes, on 15 August.

The Dalai Lama had been invited to speak at November's meeting in Washington on the effects of meditation on the brain. But some neuroscientists said that a talk by the Buddhist leader was inappropriate at an academic meeting (see Nature 436, 452;
2005). Others accused the Dalai Lama of spreading religious ideas under the guise of scientific research into meditation.

Four days after meeting the protesters, Barnes notified one of the petition's organizers, Bai Lu, a neuroscientist at the US National Institutes of Health, that the lecture would go ahead as planned.

The talk will be the first in a new series of lectures called "dialogues between neuroscience and society”. Joe Carey, public information director for the $\mathrm{SfN}$, says that the society's leadership "continues to believe that the original plan and purpose of the dialogues series makes sense, and that the first two invited speakers are consistent with the intent". The Dalai Lama's talk will be followed by one from architect Frank Gehry at the society's 2006 meeting in New Orleans.

Six abstracts for this year's meeting have been withdrawn by one SfN member in protest against the lecture. But since the controversy became public, the society says that it has received a lot of e-mails on the issue, nearly all of them in favour of the talk.

The president's decision, says Carey, will be the society's final word on the issue.

David Cyranoski 